Volume 3

Number 4 Critical Perspectives on Marketing

from Japan - Part 2

2018

\title{
Education, Enterprise Capitalism, and Equity Challenges: The Continuing Relevance of the Correspondence Principle in Japan
}

Masaaki Takemura

Meiji University

Follow this and additional works at: https://digitalcommons.uri.edu/mgdr

Part of the Anthropology Commons, Economics Commons, Education Commons, Marketing Commons, Other Business Commons, and the Sociology Commons

\section{Recommended Citation}

Takemura, Masaaki (2018) "Education, Enterprise Capitalism, and Equity Challenges: The Continuing Relevance of the Correspondence Principle in Japan," Markets, Globalization \& Development Review. Vol. 3: No. 4, Article 4.

DOI: 10.23860/MGDR-2018-03-04-04

Available at: https://digitalcommons.uri.edu/mgdr/vol3/iss4/4

This Article is brought to you for free and open access by DigitalCommons@URI. It has been accepted for inclusion in Markets, Globalization \& Development Review by an authorized editor of DigitalCommons@URI. For more information, please contact digitalcommons-group@uri.edu. 
Education, Enterprise Capitalism, and Equity Challenges: The Continuing Relevance of the Correspondence Principle in Japan

\section{Cover Page Footnote}

The reviewing of this paper was handled entirely by MGDR co-editor Deniz Atik. The author is grateful to MGDR editor Nikhilesh Dholakia and to MGDR reviewers for detailed help in the development of this paper. 


\section{Markets, Globalization \& Development Review}
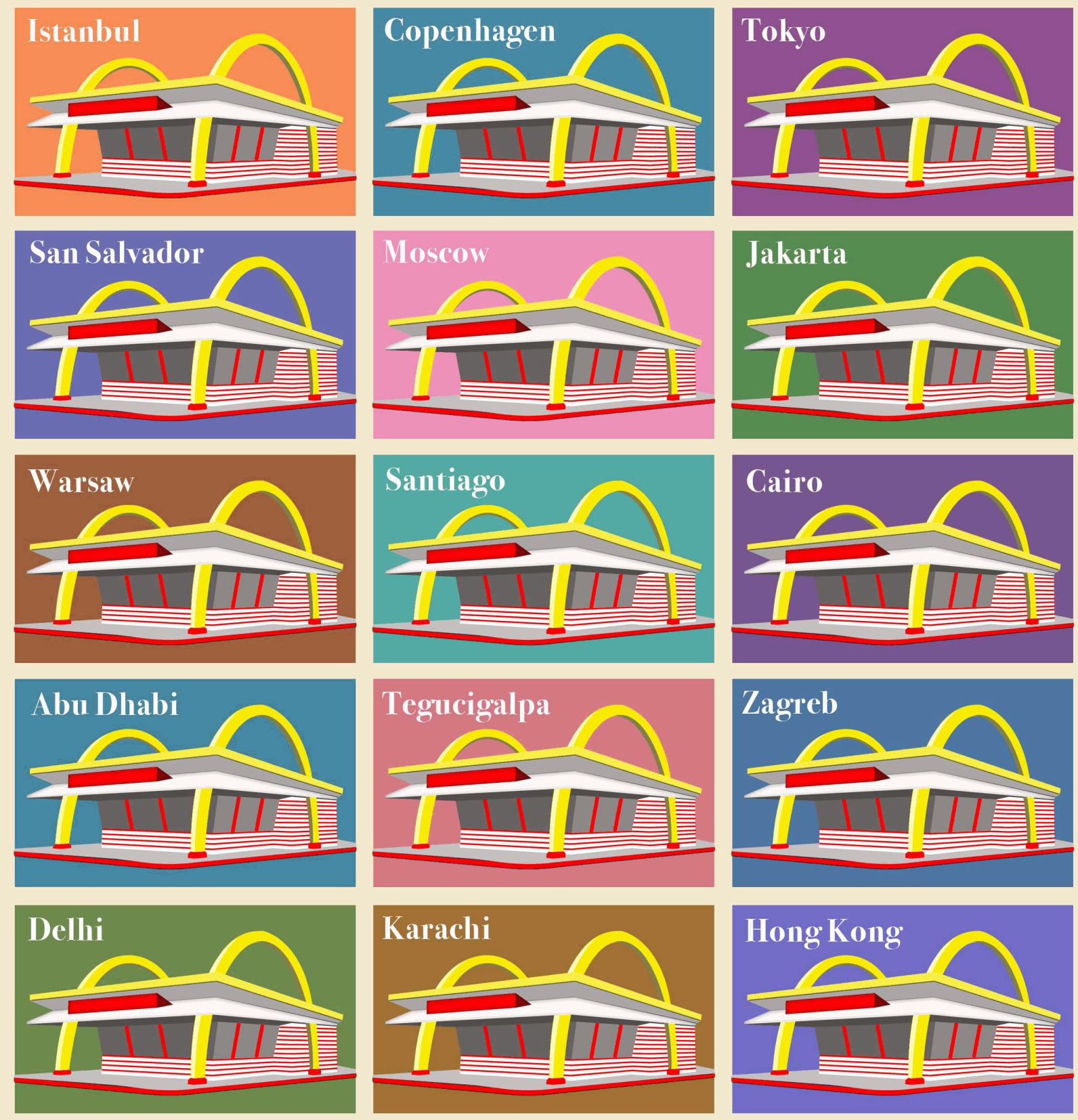

This article is available in Markets, Globalization \& Development Review: https://digitalcommons.uri.edu/mgdr/vol3/ 


\section{Education, Enterprise Capitalism, and Equity Challenges: The Continuing Relevance of the Correspondence Principle in Japan}

\section{Introduction}

This paper argues that the correspondence principle, proposed in USA in the mid-1970s (Bowles and Gintis 1976), continues to work in the $21^{\text {st }}$ century under the Japanese educational system. This principle, Marxist in its tenor, holds that the main function of schools in capitalist societies is to indoctrinate children so they grow up to be part of a docile workforce that is hardworking, accepts authority, and does not resist exploitation by the capitalist enterprises. Since its introduction, the correspondence principle has been discussed and critiqued, and modified, several times (Bates, 1980; Bowles and Gintis 2002; Giroux 1983; Lynch 1989; Willis 1981). Olson (1983, p.78), for example, says that there are "... two of Bowles and Gintis's assumptions with which I wish to take issue. These are (1) the claim that schooling's substantive curriculum is relatively passive in producing these unequal results and (2) the strategies for school and social reform that follow from these implicit working models of school and society". Shilling (1992, p.71) has argued that Bowles and Gintis "...located the education system within the social whole, and viewed it as overdetermined by broader social structures. While they did much to refute the liberal myth that educational institutions operated independently of economic pressures, these approaches tended to write off human agency".

With the passage of over four decades, it is time to revisit this principle, in the national context of Japan. In the setting reviewed here, we will show that the Bowles-Gintis principle is neither out of date, nor exhausted in its explanatory power. Rather, the original correspondence principle successfully forecasts recent Japanese recessions. Specifically, over-pessimistic adaptation to social norms can stem from the correspondence principle, affecting schools as well as the overall economy of Japan.

Thus, this paper will reevaluate the correspondence principle by Bowles and Gintis (1976), specifically based on its practical insights. Indeed, the data from Programme for International Student Assessment (PISA) - a multinational student performance survey by the Organization for Economic Cooperation and Development (OECD) - show that some Japanese PISA outcomes can be persuasively interpreted using the Bowldes-Gintis arguments. PISA results can be interpreted in two ways. 
The first way is to compare results on mainly three themes: comprehension, scientific literacy, and mathematical literacy. Japanese students generally showed superior results over the past 15 years. The second way is to delve deeper into the contents of results. A part of this paper will discuss this second aspect in detail later.

In what follows, first we will briefly review the correspondence principle and related discussions. Second, we will also briefly introduce PISA survey, with a focus on and discussion of Japan results. Third, prior to summarizing and concluding, we present an analytical framework for PISA results, mainly based on critical theory.

\section{The Correspondence Principle Revisited}

The correspondence principle (Bowles and Gintis 1976) was fundamentally based on Marx's idea in "A contribution to the critique of political economy." Bowles and Gintis (modified and) cited from the very famous Preface: "In the social production which men carry on they enter into definite relations which are independent their will ... The sum total of these relations of production constitutes... the real foundation on which rise legal and political superstructure and to which correspond definite forms of social consciousness" (Marx 1857, p.11). Bowles and Gintis (1976) saw the same structure in U.S. education. Indeed, they wrote, "The educational system helps integrate youth into the economic system, we believe, through a structural correspondence between its social relations and those of production" (Bowles and Gintis 1976, p.131). Let us visit this principle and its original temporal setting in some detail.

\section{School Reform in Retrospect}

First, Bowles and Gintis (1976) saw U.S. education system around 1960s as a form of liberalism a la Dewey (1916). Drawing on Dewey, they summarized three functions of education. The first one is the integrative function of education, which "... helps force youth into the various occupational, political, familial, and other adult roles required by an expanding economy and a stable polity" (Bowles and Gintis 1976, p.21). The second one is egalitarian function: "Schooling can not only assure fair competition, but can also reduce the economic gap between the winners and the losers. This role of schooling in the pursuit of equality of opportunity, or of equality itself... [is] the "egalitarian" function of education" (Bowles and Gintis 1976, p. 21). And the third one is the "developmental" function, in terms of promoting psychic and moral maturity: "This personal fulfillment depends, in large part, on the extent, direction, and vigor of development of our physical, cognitive, emotional, aesthetic, and other potentials" (Bowles and Gintis 1976, p.21). 
Based on this liberal view of schools, corporate leaders, university presidents, trade union officials, and politicians expected the U.S. education system to be the solution for America's social ills. Education became the chosen instrument of social reformers. President Lyndon B. Johnson proclaimed that, "... the answer for all our national problems comes down to a single word: education". In the 1960s, thus, in the U.S. education system, multiple reforms and new experiments were tried. Typical examples were "compensatory education", "Project Headstart and Title l", "school integration", and "the open classroom" (Bowles and Gintis 1976, p. 8).

Most of these reform efforts had disappointing results. Bowles and Gintis (1976, p. 48) concluded that the "... proliferation of special programs for the equalization of educational opportunity had precious little impact on the structure of U.S. education, and even less on the structure of income and opportunity in the U.S. economy. It is clear that education in the United States is simply too weak an influence on the distribution of economic status and opportunity to fulfill its promised mission as the Great Equalizer".

\section{Intergenerational Transmission of Economic Inequality}

Contrary to the conventional beliefs about the equalization effects of education, several opposite findings were reported. Coleman et al. (1966) conducted the huge surveys of 600,000 students and 60,000 teachers from 4,000 of the nation's public schools. Their conclusions showed mainly negative evaluations in terms of financial redistribution that would correct educational (and income) inequality.

Bowles (1971) doubted the equalizing effects of education. He offered, instead, four unconventional opinions: (1) the U.S. school system had evolved to meet the needs of capitalist employers for a disciplined and skilled labor force, and to provide a mechanism for social control in the interests of political stability; (2) there was the entrenched class structure which reproduced inequality from one generation to the next; (3) the U.S. school system was pervaded by class inequalities, which had shown little sign of diminishing over the last half century; and (4) there were few explanations about the persistence and pervasiveness of inequalities in the school system.

Jensen (1969), however, expressed objections against these institutional reasons (educational system) for social and economic inequalities. Rather, he asserted that these inequalities were based on genetically inherited IQ differences; thus education could not change and modify these inequalities. In the same vein, Herrnstein (1971) asserted that distributions of social and economic outcomes were determined 
predominantly by IQ distribution; also, IQ was largely an inherited trait.

Bowles and Nelson (1974) empirically revealed that among white high school seniors, those whose parents were in the top education decile were, on the average, well over three grade levels in measured scholastic achievement ahead of those whose parents were in the bottom decile (Bowles and Nelson 1974, p.32, Table 3 summarized). Bowles and Gintis (1976, p.88) realized that "a fundamental error in the liberal theory of a trend toward equality of economic opportunity is the notion that inequality of income and inequality of economic opportunity are fundamentally distinct and analytically separate phenomena. Our approach is to explain both forms of inequality as inseparable manifestations of the underlying structure of economic life. Specifically, we offer evidence that both forms of inequality are directly related to the market and property relationships which define the capitalist system, to the social relationships of work, and to the tendency toward uneven development".

\section{The Correspondence Principle}

Bowles and Gintis (1976, p.49) recognized that "the structure of U.S. education did not evolve in a vacuum; nor will it be changed, holding other things constant". They discerned the fundamental problem of social and economic inequalities. While Bowles and Gintis did not use such terms explicitly, it was clear to them that the main causal factor was the capitalist corporate enterprise economy - corporate capitalism. They did discuss the dominance of hierarchical bureaucratic corporations - the essence of corporate capitalism. Thus, "the accepted ideology is the technocratic-meritocratic perspective. The chosen structure of social relationships is the hierarchical division of labor and bureaucratic authority of corporate enterprise. The system of stratification is by race, sex, education, and social class, which often succeeds admirably in reducing the creative power and solidarity of workers "(Bowles and Gintis 1976, pp. 55-56). They showed that the reproduction of the power relations of economic life. The systemic was that the quality of work life was inimical to healthy personal development and indeed, the structure of power in the economy thwarted full human development. Overall, they suggested that economic inequality was a structural aspect of the capitalist economy and did not derive from individual differences in skills and competencies.

\section{Controversy around the Correspondence Principle}

As soon their book was published, controversies erupted. One critique was that the principle predestinated the teleology of the social relations between production and education. Such critics saw an extreme functionalism element in the correspondence principle. Giroux (1983) said 
that "Unfortunately, the economic-reproductive model had failed to capture the complexity of the relationship between schools and such other institutions as the workplace and the family. Within its grimly mechanistic and overly determined model of socialization, there appears little room for developing a theory of schooling that takes seriously the notions of culture, resistance, and mediation" (Giroux 1983, p. 266).

Another critique was about the logical relation between social stratifications and educational stratifications. Bates (1980) indicated that 'Bowles' and Gintis' argument [does not] illuminate the mechanisms through which social and educational stratification are related" (Bates 1980, p. 72). In the same vein, Lynch (1989) noticed that "Bowles and Gintis fail to explain how the structural correspondence between schools and the capitalist economy actually occurs. A highly mechanistic and deterministic relationship is assumed to exist between the economy and the school system. This both ignores the complexities of the class structure and class interests in contemporary capitalist society, and the fact that schools as organizations are dynamic and self-interested social entities in themselves" (Lynch 1989, p. 5).

While such critiques do have some power, the correspondence principle can still describe and explain well many aspects of the education system - especially in a context like Japan.

\section{Education System in Japan and PISA Results}

This section will attempt three things: (1) description of the contemporary Japanese education system; (2) presenting and discussion of some of the PISA results in Japan; and (3) linking the Japanese education system and the PISA results to the Bowles-Gintis correspondence principle.

\section{Contemporary Japanese Education System}

Traditionally, Japanese education system receives high international accolades. Ellington (1992) found three "high score" activities in Japan's schooling: (1) Over $95 \%$ of students, during first nine years of compulsory education, attended public schools; (2) Over $90 \%$ of Japanese youth graduated from high school; and (3) High performance in the entrance examinations for both high schools and universities.

Rohlen (1986) evaluated Japanese education system in terms of Japan's economic competitiveness. He stated: "It is not surprising to discover that during the last twenty years Japan had quietly been establishing a new, higher set of educational standards for the world. On a whole raft of international tests of achievement in science and math, Japanese students outperform all others"; and, furthermore, he suggested that "Japan is "meritocracy" shaped by an educational competition that 
enrolls nearly everyone. And this is fitting, for japan is a nation that, lacking natural resources, must live by its wits, by social discipline, and by plain hard work" (Rohlen 1986, p. 30). The PISA results, from this century, echo these earlier themes.

\section{PISA Results}

The first PISA was conducted in 2000 and it is repeated every three years. The primary purpose of PISA is to obtain comparable data that provide the participant countries information to improve their education systems and policies. In each country surveyed by OECD, at least 5000 students are part of the sample. Students take two-hour examinations about reading comprehension, mathematical literacy, and scientific literacy, respectively. Some of the test items are multiple-choice, some of them entail descriptive writing. In 2015, 72 countries and about 540 thousand students participated in PISA evaluations.

In Japan, 198 schools and about 6600 students participated. The number of participant countries and Japan's score and rankings are listed in Table 1. To avoid country differences and bias, raw scores are scaled so that the OECD average in each examination (reading, mathematics, and science) is 500 and the standard deviation is 100. Table 1 shows Japanese PISA results.

Table 1: Japanese PISA Results and Japan's Ranking

\begin{tabular}{|c|c|c|c|c|c|c|c|}
\hline & & 2000 & 2003 & 2006 & 2009 & 2012 & 2015 \\
\hline \multirow{2}{*}{$\begin{array}{l}\text { Reading } \\
\text { Comprehension }\end{array}$} & Score & 522 & 498 & 498 & 520 & 538 & 516 \\
\hline & Rank & 8 & 14 & 15 & 8 & 1 & 8 \\
\hline \multirow{2}{*}{$\begin{array}{l}\text { Mathematical } \\
\text { Literacy }\end{array}$} & Score & 557 & 534 & 523 & 529 & 536 & 532 \\
\hline & Rank & 1 & 6 & 10 & 9 & 7 & 5 \\
\hline \multirow{2}{*}{$\begin{array}{l}\text { Scientific } \\
\text { Literacy }\end{array}$} & Score & 550 & 548 & 531 & 539 & 547 & 538 \\
\hline & Rank & 2 & 2 & 6 & 5 & 4 & 2 \\
\hline $\begin{array}{l}\text { Participating } \\
\text { Countries }\end{array}$ & & 32 & 41 & 57 & 65 & 65 & 72 \\
\hline
\end{tabular}

From Table 1, three points emerge. First, Japan's results are often better than the OECD averages are. Second, Japan's results often fluctuated. The fluctuations can be traced to the educational policy changed since 2002. That policy aimed to reduce schooling hours, require two-days holiday in a week, and adjusted curricula. And third, there are 
differences of scores across types of examinations. Scientific literacy generally achieves higher rank than the other two. Reading and mathematics do not achieve stable results. Overall, though, we can see that Japan's educational results represent good performance in general.

\section{PISA School Life Survey and the Correspondence Principle}

Besides scores and ranks, other interesting results can be found in the PISA 2009 survey. Maita (2016), writing in Japanese, released some polemic findings about PISA results. Here, we introduce Maita's method and interpret his idea in English, and also provide some additional and original information.

Maita (2016) focused on disciplinary climate in Japan. Disciplinary climate is defined as classroom conditions that affect learning. Foreign pedagogy researchers, visiting schools in Japan, were impressed that the classroom disciplinary climate was stable and calm: e.g., quiet, tidy, and well-organized operations.

Maita suggested, however, that the reason for such observed conditions was not the advanced intellectual level, nor academic attitude; rather what was evident was students' ritualistic strategy to maintain the class condition. According to Maita's method, disciplinary climate can be measured by two variables: disturbance level of the class and relationship with teachers. As measurements of the class condition, he focused on these three PISA questions:

a) I get along well with most of my teachers.

a) Students don't listen to what the teacher says.

b) There is noise and disorder.

In Figure 1, the horizontal axis represents the proportion of all students who replied to the statement "students don't listen to what the teacher says," as "Never or hardly ever". The 92\% proportion for Japanese students indicate that students listen to what the teacher says. Similarly, the vertical axis score in Figure 1 shows strong disagreement with "noise and disorder' in classroom. According to PISA 2009 results, "across OECD, the index of disciplinary climate is highest in Japan and Korea. The index of disciplinary climate in Korea is one-third of a standard deviation higher than that of the OECD average, and Japan has a disciplinary climate that is three-quarters of a standard deviation higher than the OECD average level." (PISA 2009, p. 90). 
Figure 1: International Comparisons on School Disorder

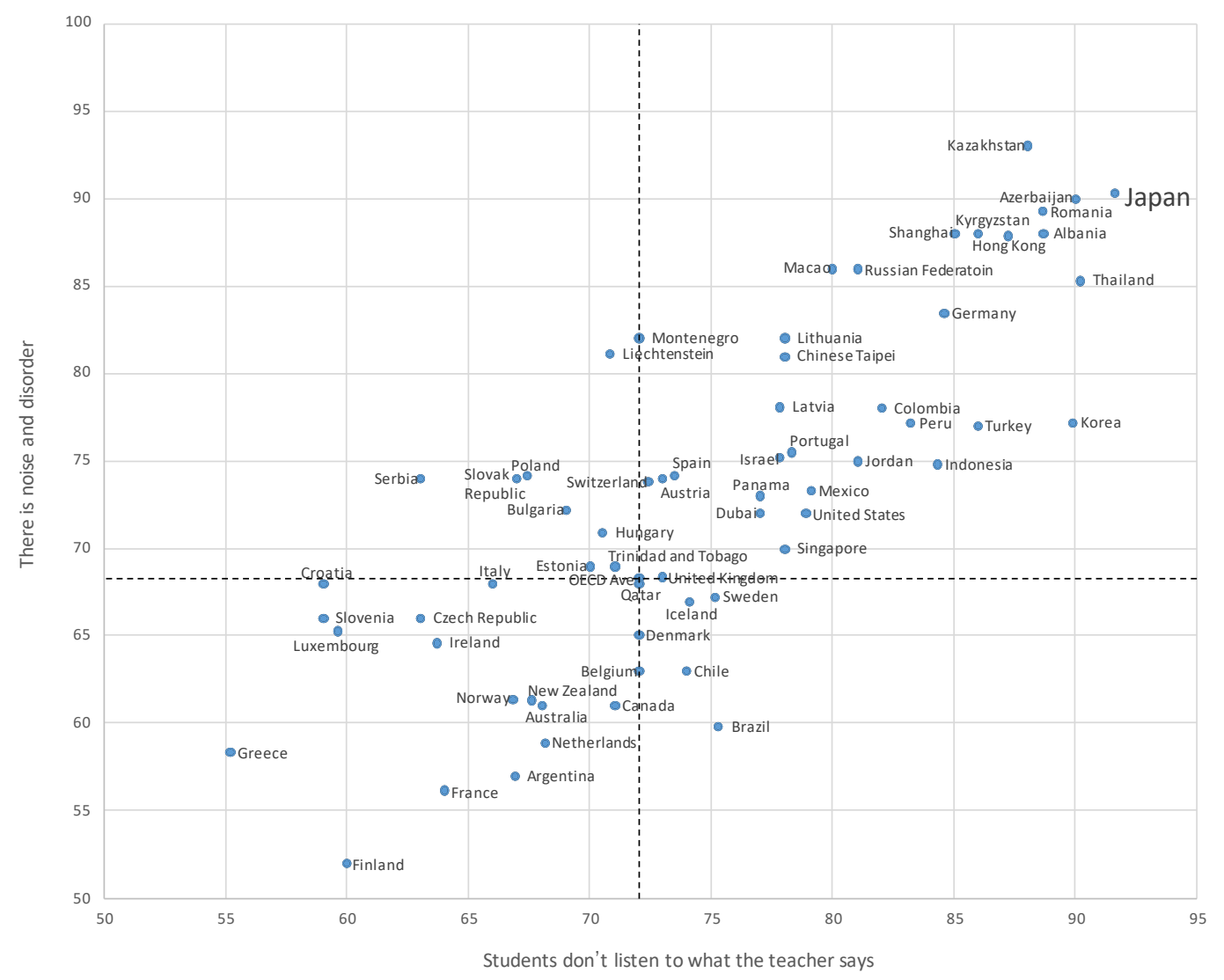

Source: PISA 2009 Results Volume IV, p. 89 and p.91

From Figure 1, it is natural to assume that Japanese students establish good relationships with their teachers. In Figure 2, the horizontal axis is the same as in Figure 1, indicating that the students in Japan listen to their teachers. The vertical axis in Figure 2 is a measure of "I get along well with most of my teachers". Here, Japan has the lowest score in the world. Paradoxically, the Japanese students listen to their teachers but do not get along well with their teachers. Korea has a similar pattern. Why is this so? Maita (2016) argued that Japanese students executed a ritualistic strategy, in terms of the sociological framework of Merton (1938). 
Figure 2: International Comparisons of Student-Teacher Relationships

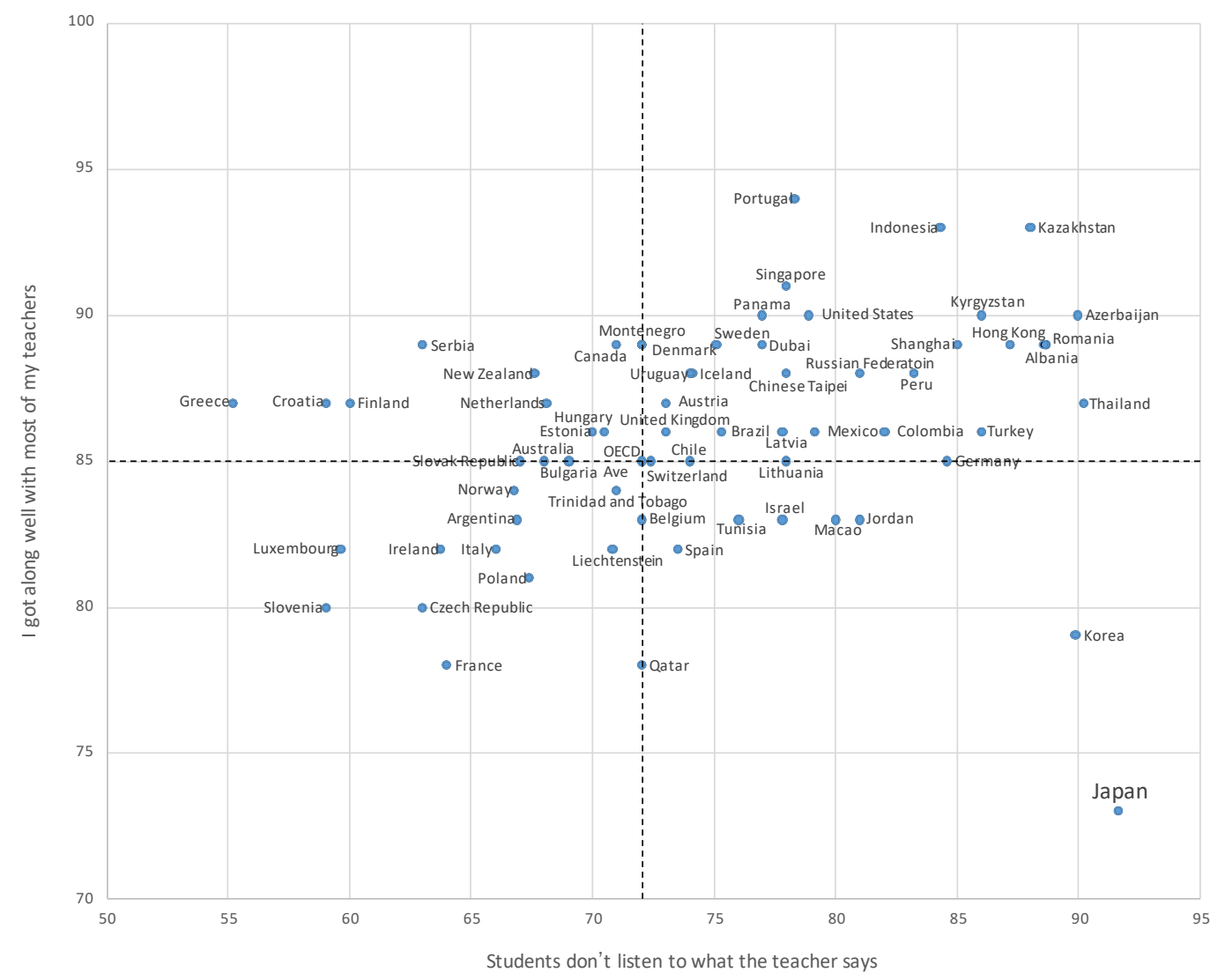

Source: PISA 2009 Results Volume IV, p. 89 and p. 91

\section{Critical Discussion on Japanese Education-Job Recruiting Structure}

To summarize the discussion on Japanese results of PISA surveys:

1) Educational results show better performance than most other countries.

2) Japanese school disciplinary climate is one of the best, globally.

3) Yet, Japanese students do not establish good relationships with their teachers.

To reiterate this paradox: Japanese students keep the classroom calm and listen to what their teachers say; yet, the students do not establish good relationships with their teachers. To explain, we turn to the sociological work of Merton; and this leads to a Japanese interpretation of 
the Bowles-Gintis correspondence principle. Some discussion is provided as to why this reproduction structure is maintained in Japan.

\section{Merton's Acceptance Models}

One of Robert Merton's seminal works was his theory of anomie (Merton 1938), explaining how people cope with social disorder (derangement and an insatiable will, a la Durkheim). According to his framework, social structure was maintained by joint operation of two elements, cultural goals and institutional norms (Merton 1938, p. 673). Anomie occurs when these two elements become disordered.

To deal with anomie, Merton (1938) formalized four (actually five) types of 'acceptance models': conformity, innovation, ritualism, and retreatism; and later added the non-acceptance mode of rebellion. Indeed, Conformity leads a person to adapt to both cultural goals and institutional means. In the innovation response, conflict and frustration are eliminated by relinquishing the institutional means and retaining the success-aspiration. Ritualism is the opposite of innovation. It entails accepting institutional means, but rejecting cultural goals. Finally, retreatism entails rejecting the institutional means and the cultural goals.

Ritualism provides the best interpretation of Japan's PISA results. Japanese students are strongly fixated on their educational goals by culture. Also, the institutional means to be successful are given by culture as well. Let is probe the relations between the ritualism adaptation and Japanese students' behaviors.

\section{The Japanese Correspondence Principle}

Figure 3 is a way to illustrate the correspondence principle, as observable in Japan. This figure provides a way to visually link Bowles and Gintis's (1976) correspondence principle, the paradoxical PISA results of Japan, and Merton's anomie adaptation model - especially the ritualism response. The figure has three elements, each element having its original mission as well as its unanticipated effects. Of course, these three elements link to each other. The Japanese job system is characterized by a ritualized recruiting procedure. The Japanese education system is characterized by an upgrade orientation. This orientation has been established historically by Japanese culture and supported by general social beliefs. Finally, student attitude is formed by education system and cultural orientations. 
Figure 3: The Japanese Correspondence Principle

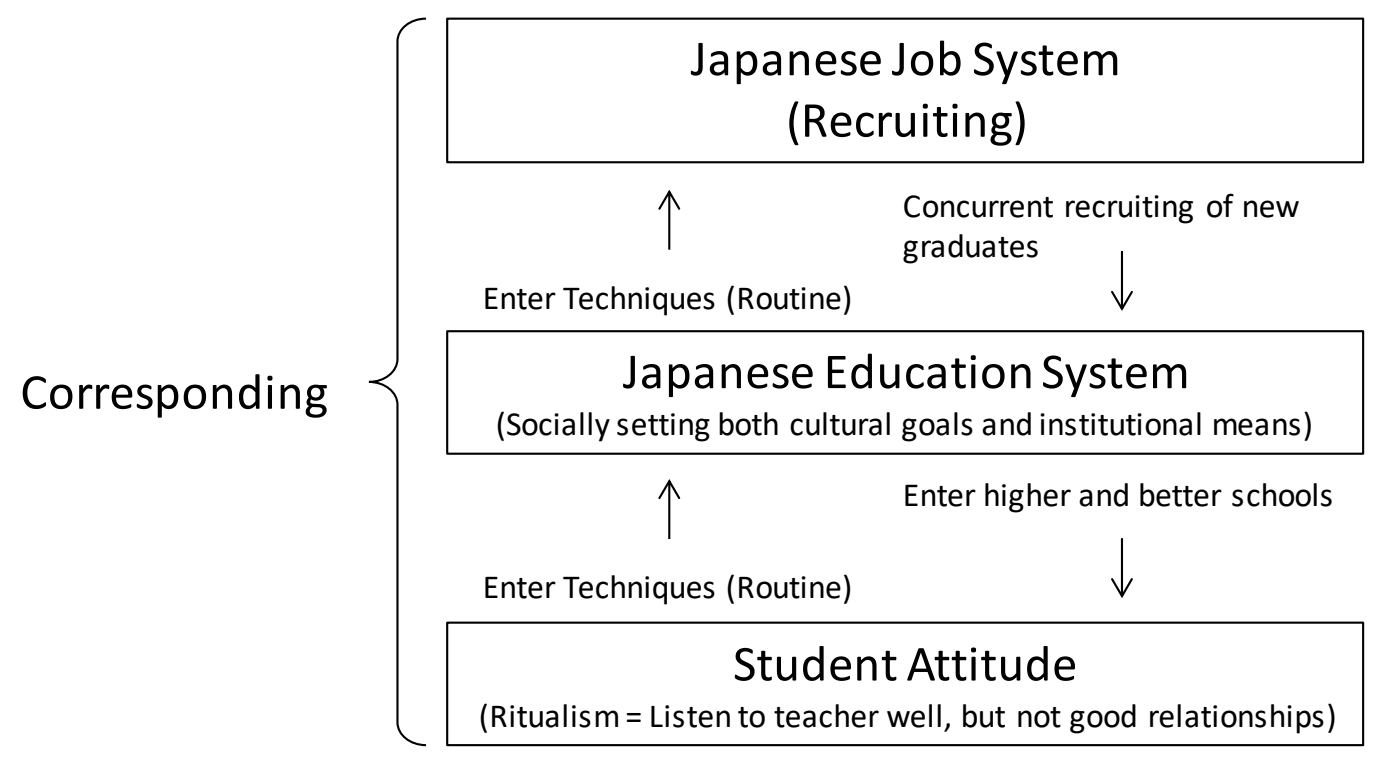

Each element has its own independent logic. Japanese job recruiting system is unique, that is, one-time (annual) employment event. In March every year, such recruitment happens for new graduates from any school (university: 22-year olds, college: 20-year olds, high-school: 18-year olds, and junior high-school: 15-year olds). Of course, other opportunities exist, but Japanese companies generally and mainly focus on this annual event. It is of course extremely efficient; only one event to obtain all new employees.

The Japanese education system has its own logic. The Basic Act on Education of Japan states as Preamble, "We, the citizens of Japan, desire to further develop the democratic and cultural state we have built through our untiring efforts, and contribute to the peace of the world and the improvement of the welfare of humanity. To realize these ideals, we shall esteem individual dignity, and endeavor to bring up people who long for truth and justice, honor the public spirit, and are rich in humanity and creativity, while promoting an education which transmits tradition and aims at the creation of a new culture." (The original act \#25 was established in 1947, modified act \#120 adopted in 2006).

While each element forms its own logic, it has to adjust with others: the Japanese version of 'correspondence'. Naturally, students want to adjust their job search schedule to the annual recruiting event. University 
education system is partly subject to this recruiting rule. Therefore, the education system adjusts to this general job recruiting system, and provides curricula that adapt to the business logic. Many universities in Japan are employing curricula that, besides academics, deal with business etiquettes, business internships, businessperson lecture series, and so on. Of course, students are clamoring for these kinds of lectures. Indeed, Japanese students already start preparing for recruiting since 3rd grade, and the preparations happen more than one year before graduation. In lower grade education (elementary school, junior high school, and high school), the primary objective is to progress - in terms of academic scores.

To adjust to this recruiting system, students who graduate from a university can have better opportunities than any other students. Thus, most of all actors surrounding the student - parents, sisters and brothers, and teachers - constantly urge the student to advance to upper-level schools.

\section{Critical Analysis of Japanese Education Performance}

During their school years, students learn two things. The first one is academic knowledge. The second one is knowledge of how to survive in the school environment. The latter is not so much learning as it is cultural accustoming and adapting. The relations among the three elements of Figure 3 can be summarized in Table 2 .

\section{Table 2: Original Purposes and Unanticipated Results}

\begin{tabular}{|l|l|l|}
\hline System & Original Purposes & Unanticipated Results \\
\hline Recruiting system & $\begin{array}{l}\text { To hire creative, } \\
\text { innovative, } \\
\text { challengeable persons }\end{array}$ & $\begin{array}{l}\text { Adaptive dexterous } \\
\text { persons }\end{array}$ \\
\hline Education system & $\begin{array}{l}\text { To develop the abilities } \\
\text { of individuals while } \\
\text { respecting their value; } \\
\text { cultivate their creativity; } \\
\text { foster a spirit of } \\
\text { autonomy and } \\
\text { independence; and } \\
\text { foster an attitude to } \\
\text { value labor while } \\
\text { accumulation; to } \\
\text { advance higher } \\
\text { education opportunities; } \\
\text { to attain orthodox } \\
\text { solutions; to avoid } \\
\text { emphasizing the } \\
\text { connections with career } \\
\text { and }\end{array}$ & $\begin{array}{l}\text { ways. } \\
\text { and practical life. } \\
\text { (Objectives of } \\
\text { education, Article 2 (ii) }\end{array}$ \\
\hline
\end{tabular}




\begin{tabular}{|l|l|l|}
\hline System & Original Purposes & Unanticipated Results \\
\hline School system & $\begin{array}{l}\text { The schools prescribed } \\
\text { by law shall be of a } \\
\text { public nature, and only } \\
\text { the national } \\
\text { government, local } \\
\text { governments, and } \\
\text { juridical persons } \\
\text { prescribed by law shall } \\
\text { be entitled to establish } \\
\text { them. (School } \\
\text { admission to master } \\
\text { aducation, Article 6) }\end{array}$ & $\begin{array}{l}\text { techniques; few creative } \\
\text { aspects in the } \\
\text { curriculum. }\end{array}$ \\
\hline
\end{tabular}

This table points to the unanticipated results or consequences. For socially problematic situations, Merton (1936) identified two dominant types of causes. The first one is lack of knowledge. Merton stated: "In some instances, we may have sufficient knowledge of the limits of the range of possible consequences, and even adequate knowledge for ascertaining the statistical (empirical) probabilities of the various possible sets of consequences, but it is impossible to predict with certainty the results in any particular case" (Merton 1946, pp. 898-99). The second one is error. Here, Merton stated: "Error may also be involved in instances where the actor attends to only one or some of the pertinent aspects of the situation which influence the outcome of the action" (Merton 1938, p. 901).

Furthermore, in the Japanese setting, it is useful to consider one more additional cause: tactical adaptation. Tactical adaptation describes achieving anticipated results, but that deviate from the original purpose. This consequence stems from many factors. For instance, Japanese Basic Act on Education states that "The objectives of education is to foster an attitude to acquire wide-ranging knowledge and culture, and to seek the truth, cultivate a rich sensibility and sense of morality, while developing a healthy body." (Article 2 (i)). Of course, there are many means to achieve this.

Most of Japanese students recognize that the primary purpose of learning is to gain technical skills for advancing upper-level schools. Under this reality, the magnificent and noble mission statement in the Basic Act on Education appears superficial, of little practical value.

Students, unable to find the original educational purpose by lectures and good relationship with teachers, only fixate on their current positions and their ability to advance to the next higher level. This is what the paradoxical PISA results for Japan show - generally high achievement, seemingly disciplines classroom settings, but no great student-teacher 
relationships and relatively few opportunities for creative and innovative work.

\section{Conclusions}

This paper discussed some of the results that the Japanese education system yielded in the past two decades. Japanese students perform better than many other countries and keep performing better for a long time, even though many students do not enjoy school or their classes.

The totality of the Japanese education system might be the cause of this interesting, contradiction-laced result. The Japanese education system is embedded in rigid linkages across enterprise capitalism and Japanese education policy. Many Japanese still believe that educational success happens when a student enters into higher reputation schools (the so-called them Brand-name Schools). To graduate from higher reputation schools seems to persist as the necessary condition to have a better job in Japan.

This rigid linkage resonates with the correspondence-principle logic of Bowles and Gintis (1976). They showed how this unequal relationship corresponds with that of the workplace - the boss and his staff. Therefore, the school simply teaches young people (via latent aspects of the curriculum) to accept social inequalities in the workplace, as exemplified and reinforced by the 'teaching' and rule structures at the schools. Thus, schools train:

- students to accept authority by having to follow school rules without question - as business persons have to at work.

- students to accept the norms and values of the workplace - poor attendance and lateness are punished as it would be at work.

- students to inculcate the importance of looking smart - they are punished for wearing trainers to school or sent home if, for girls, the skirt is too short - as is likely in some jobs.

Everyone in Japan knows and internalizes this irrational correspondence principle. Very few creative students, or freewheeling members of young generations, have emerged in recent years. The structure remains rigid and rigorous ever. To achieve academic excellence, most parents and students engage with a parallel marketplace of onerous, late-evening coaching classes. Every year, students rush to attend the recruiting seminars that are held at the top-choice universities. The Bowles-Gintis correspondence principle continues to thrive and keeps reproducing itself in Japan. 


\section{References}

Bates, Richard J. (1980), "New Developments in the New Sociology of Education," British Journal of Sociology of Education, 1 (1), 67-79. https://doi.org/10.1080/0142569800010105

Bowles, Samuel (1971), "Unequal Education and the Reproduction of the Social Division of Labor," Review of Radical Political Economics, 3 (4), 1-30. https://doi.org/10.1177/048661347100300401

Bowles, Samuel and Valerie I. Nelson (1974), "The "Inheritance of IQ" and the Intergenerational Reproduction of Economic Inequality," Review of Economics and Statistics, 56 (1), 39-51. https://doi.org/10.2307/1927525

Bowles, Samuel and Herbart Gintis (1976), Schooling in Capitalist America: Educational Reform and the Contradictions of Economic Life. Chicago: Haymarket Books.

Bowles, Samuel and Herbert Gintis (2002), "Schooling in Capitalist America Revisited," Sociology of Education, 75 (1), 1-18. https://doi.org/10.2307/3090251

Coleman, James S., Ernest Campbell, Carol Hobson, James McPartland, Alexander Mood, Frederick Weinfeld and Robert York (1966), Equality of Educational Opportunity. Washington, D.C.: U.S. Office of Education.

Ellington, Lucien (1992), "Japanese Education," Japan Digest, The National Clearinghouse for United States-Japan Studies, Indiana University, (accessed January 28, 2018), [available at https://files.eric.ed.gov/fulltext/ED359086.pdf]

Dewey, John (1916), Democracy and Education: An Introduction to the Philosophy of Education. New York: Macmillan.

Giroux, Henry (1983), "Theories of Reproduction and Resistance in the New Sociology of Education: A Critical Analysis," Harvard Educational Review, 53 (3), 257-93. http://dx.doi.org/10.17763/haer.53.3.a67x4u33g7682734

Herrnstein, Richard J. (1969), "IQ," Atlantic Monthly, 228 (3), 43-64.

Jensen, Arthur A. (1969), "How Much Can We Boost IQ and Scholastic Achievement?" Harvard Educational Review, 39 (1), 1-123. http://dx.doi.org/10.17763/haer.39.1.I3u15956627424k7

Lynch, Kathleen (1989), The Hidden Curriculum: Reproduction in 
Education, A Reappraisal. Philadelphia, PA: The Falmer Press.

Maita, Toshihiko (2016), "Nihon no seito ha "girei teki" ni kyousi ni shitagatte iru dake (Japanese Students "Courteously and Ritualistically" obey their teachers.)," Newsweek, June 7, 2016. (accessed December 30, 2017), [available at https://www.newsweekjapan.jp/stories/world/2016/06/post-5268 1.p $\underline{\mathrm{hp}}]$

Marx, Karl (1857), Contribution to a Critique of Political Economy, (translated from the 2nd German edition by Nahum Isaac Stone, 1904), Chicago: Charles H. Kerr Publishing.

Merton, Robert K. (1936), "The Unanticipated Consequences of Purposive Social Action," American Sociological Review, 1 (6), 894-904. https://doi.org/10.2307/2084615

Merton, Robert K. (1938), "Social Structure and Anomie," American Sociological Review, 3 (5), 672-82. https://doi.org/10.2307/2084686

OECD (2010), PISA 2009 Results: What Makes a School Successful?: Resources, Policies and Practices (Volume IV), http://dx.doi.org/10.1787/9789264091559-en

Olson, C. Paul (1983), "Inequality Remade: The Theory of Correspondence and The Context of French immersion in Northern Ontario," Journal of Education, 165 (1), 75-98. https://doi.org/10.1177/002205748316500107

Rohlen, Thomas P. (1986), "Japanese Education: If They Can Do It, Should We?" American Scholar, 55 (1), 29-43.

Shilling, Chris (1992), "Reconceptualising Structure and Agency in the Sociology of Education: Structualisation Theory and Schooling," British Journal of Sociology and Education, 13 (1), 69-87.

Willis, Paul (1981), "Cultural Production is Different from Cultural Reproduction is Different from Social Reproduction is Different from Reproduction," Interchange, 12 (2/3), 48-67. https://doi.org/10.1007/BF01192107 